\title{
From forgetfulness to dementia:
}

\author{
clinical and commissioning implications of diagnostic experiences
}

\begin{abstract}
Background

The National Dementia Strategy in England stressed the importance of earlier diagnosis of dementia. In-depth knowledge of the experiences of patients using such services remains an evidence gap.
\end{abstract}

Aim

To increase understanding of the experiences of people developing dementia and of their carers, to inform practice and decision making.

\section{Design and setting}

A retrospective and prospective qualitative interview study of participants recruited from four memory clinics in London, the north-west and the north-east of England.

\section{Method}

Purposive sampling was used to recruit 27 individuals with memory problems and 26 supporters and carers. Interviews explored referral pathways, assessment processes, disclosure of the diagnosis, experiences of being prescribed medication to help with symptoms, and issues of risk and decision making.

\section{Results}

Few participants experienced the process of memory assessment as patient centred. Where assessment processes were lengthy and drawn out, participants experienced considerable uncertainty. Many experienced tests and assessments as distressing, sometimes in settings that were perceived as alarming or potentially stigmatising by association. Information provision and communication were variable and practitioners were not always thought to help people to make sense of their experiences.

\section{Conclusion}

The transition from the early stages of cognitive impairment is not straightforward. There is potentially much uncertainty and waiting. Primary care practitioners may be better able to provide tailored support to individuals and their carers during this time if they are aware of what patients are anticipating and are informed about the diagnostic "journey' by the insights of those who have experienced it.

\section{Keywords}

Alzheimer's disease; dementia; dementia, policy: diagnosis; early intervention; mental health services.

\section{INTRODUCTION}

Anxieties about loss of cognition are commonly expressed by older people, ${ }^{1,2}$ and it is hard for the British public to ignore the risks of cognitive impairment in later life, ${ }^{3}$ in light of a major television advertising campaign aiming to raise awareness of dementia. ${ }^{4}$ Worldwide, populations are ageing, ${ }^{3}$ and life expectancy continues to increase at the rate of approximately 2 years per decade. ${ }^{5}$ Consequently, the prevalence of cognitive impairment and probable dementia will also rise, ${ }^{6,7}$ and such patients and their family members will be increasingly encountered in general practice.

There is international consensus favouring earlier diagnosis of dementia, ${ }^{8}$ although concern exists that both the benefits and risks need to be better appreciated. ${ }^{9}$ From Canada, as elsewhere, primary care physicians report that it is not always easy to provide supportive care because of time constraints, emotional burden, and jurisdictional issues. ${ }^{10}$ While some individuals may find being diagnosed with dementia distressing, reported advantages include developing a better understanding of the situation, an end to uncertainty, the ability to plan, access to practical and emotional support, and the chance to develop positive coping strategies. ${ }^{11,12}$ In England, the government expressed its commitment to early diagnosis in the National Dementia Strategy, ${ }_{13}^{13}$ repeated this in its refreshment of the strategy, ${ }^{14}$ and resourced this with a further $€ 10$ million to fund near-national coverage by memory services. ${ }^{15}$

The National Dementia Strategy highlighted the need to provide information and advice to individuals with dementia prior to, during, and after the diagnostic process..$^{13}$ It is here, at these processes of transition, that the individual concerned may be acquiring the identity of an individual with dementia', both in their own minds and in the views of others. Hazards in the diagnostic process include stigmatisation and loss of autonomy and control. ${ }^{16,17}$ Those who commission assessment services are recommended to ensure these can Advise on the immediate treatment, care and support that is needed for individuals with dementia and their carers, signposting individuals to the appropriate services and resources'. ${ }^{15}$

A dearth of research about the experiences of individuals with dementia emerged in the National Institute for Health and Clinical Excellence/Social
J Manthorpe, BA, MA, professor of social work; K Samsi, BA, MSc, PhD, research fellow, King's College London, Social Care Workforce Research Unit, London. S Campbell, BSc, research associate; J Keady, PhD, RMN, RMT, professor of older people's mental health nursing, School of Nursing, Midwifery and Social Work, University of Manchester, Manchester. C Abley, BSc, MSc, $\mathrm{PhD}, \mathrm{RGN}$, research fellow; J Bond, BA, professor of social gerontology and health services research; L Robinson, MRCGP, MD, professor of primary care and ageing, Newcastle University, Institute of Health and Society, Newcastle-upon Tyne. S Watts, consultant clinical psychologist, Greater Manchester West Mental Health NHS Foundation Trust, Prestwich, Manchester.

J Warner, BSc, MD, MRCP, FRCPsych, consultant psychiatrist, Central and North West London NHS Foundation Trust, London, reader in psychiatry,
Imperial College London, London. S Iliffe, FRCGP, FRCP, professor of primary care for older people, University College London, Primary Care and Population Health, Royal Free University College Medical School, London.

\section{Address for correspondence}

Jill Manthorpe, Social Care Workforce Research Unit, King's College London, WC2R 2LS, UK.

E-mail: jill.manthorpeakcl.ac.uk

Submitted: 19 March 2012; Editor's response: 1 May 2012; final acceptance: 16 May 2012. (CBritish Journal of General Practice

This is the full-length article (published online 31 Dec 2012) of an abridged version published in print. Cite this article as: Br J Gen Pract 2013; DOI: 10.3399/bjgp13X660805 


\section{How this fits in}

The article provides insight into the way people with memory problems experience memory assessment and diagnosis. It highlights that, in the main, people with memory problems do not feel assisted to make sense of their experiences during assessment and diagnosis. More specifically, clinicians and commissioners should be aware that delays in the diagnostic process may prolong uncertainty and distress, with the risk that misunderstandings may be confounded or arise if individuals are not given clear information about specific treatment options. The environment of assessment and appointments also impacts on individuals, with home appointments generally being more positively experienced.

Care Institute for Excellence (NICE/ SCIE) dementia guidelines. ${ }^{18}$ However, individuals' experiences have not been entirely overlooked. Research has identified concerns about the personal threat of dementia in later life, ${ }^{2}$ and of 'anticipatory dementia' among those attending for memory appraisal. ${ }^{19,20}$ More recent research describes the views, experiences, and coping strategies of individuals with dementia following diagnosis. A range of reactions is reported, from positive responses through to depression, grief, and active denial. ${ }^{21-23}$ Studies of individuals undergoing assessment land of their carers) have revealed equivocal views about the adequacy of information supplied, ${ }^{24}$ and concerns about clinicians' ability to identify information needs and respond effectively; ${ }^{25}$ observations that have similarly arisen in the Netherlands. ${ }^{26,27}$

A literature review undertaken as part of the current study, which focused on the process of disclosure of dementia diagnosis, revealed wide variability in reported practice, with theoretical 'guidelines' that did not reflect practice. ${ }^{28}$ Disclosure was rated by primary care physicians as causing difficulties in the management of individuals with dementia, who were less likely to use the correct terminology with patients and family members than psychiatrists. ${ }^{11}$ In addition, family members were more likely to be told the diagnosis in less euphemistic terms, than individuals with dementia. ${ }^{11}$

The aim of this study was to understand the experiences of the person who is becoming 'a person with dementia', from their perspective and that of their supporters or carers. The specific objectives were to understand the process, experiences of accessing services, assessments, treatment decisions, and encounters with health professionals before and after diagnosis, especially since the greater availability of cholinesterase inhibitors gave fresh impetus to diagnosis. The aim was to develop a model of care useful to those commissioning assessment services for individuals potentially undergoing a crucial transition.

\section{METHOD}

Interviews were undertaken with both individuals with dementia and those they nominated as carers. This qualitative study had both retrospective and prospective elements. Retrospectively, participants for whom a dementia diagnosis had already been disclosed (within the previous 3 months) were recruited and they and/ or their carer were interviewed about their experiences of the diagnostic process. The researchers also prospectively recruited memory clinic attendees referred by their GPs who had not yet received a diagnosis of dementia, and interviewed them and/or their carer about their experiences before and after the diagnostic assessment, if the diagnosis had been reached within the study timeline.

Participants were recruited from four memory clinics situated in London I $n=$ 1), north-west England ( $n=1)$, and northeast England ( $n=2$ ). Memory clinics were the recruitment source because they encounter individuals at a relatively early point in the transition to dementia. ${ }^{29}$ The three study areas were selected on the basis that together they served populations that were diverse in terms of socioeconomic status and ethnicity. Purposive sampling ${ }^{30,31}$ guided the selection and recruitment of participants, with data intentionally collected from groups that were under-represented. Active and regular engagement with the staff at memory clinics facilitated recruitment, as these were the initial gatekeepers in identifying potential participants and introducing the study to them. Regular team meetings helped identify under-represented groups, and initial sampling was expanded to recruit greater numbers of females, greater numbers of individuals living in urban and rural situations (as opposed to suburban), and wider variation in socioeconomic status. At one stage, it was decided to concentrate on recruiting individuals with dementia who had been diagnosed relatively early, because a growing proportion of the sample had received a diagnosis of mild cognitive impairment (MCI). 


\section{Box 1. Interview topic guide}

- Introductory questions

- Biographical information: about the individual, their lifestyle, living situation, nature of carer relationship

- Help-seeking behaviour leading to the first appointment at clinic

- Experience (descriptive and emotional) of initial appointments at the clinic and talking to professionals about memory difficulties

- Information received, from whom, what level of detail; what did the individual think about the way in which they received this information?

- Unmet need: regarding services, information, enough time

- Written information and communication received and unmet need

The interview topic guide drew on the literature to explore assessment processes, diagnosis disclosure, ${ }^{32}$ experiences of medications, ${ }^{33,34}$ and 'contested territories', such as risk and decision making. ${ }^{35}$ Box 1 provides brief details of the areas included in the topic guide. Terms such as 'memory problems' were used initially when talking to participants, unless or until participants themselves brought up terms such as 'dementia', 'Alzheimer's', or 'cognitive impairment'. During interviews with individuals with a diagnosis, the interviewers started with the phrase 'the diagnosis of the cause of your memory problems', to give an opportunity to participants to frame the context of the conversation.

In keeping with the Mental Capacity Act 2005, only individuals with dementia who were able to consent to participate were included as direct participants. Even so, the breakdown of language and memory in dementia may result in some individuals with dementia being able to provide only a partial view of the illness narrative as the syndrome evolves, ${ }^{36}$ or not being confident in discussion. In a number of cases, the person with dementia and their carer chose to be interviewed together. Where it was not possible to interview both members of the dyad (person with dementia plus carer), interviews were conducted with the person willing to be interviewed. This was to encourage participation of individuals with dementia without a carer, as well as to hear the views of carers whose relative with dementia might be reluctant to participate. During joint interviews, the researchers encouraged both participants to share their views on topics discussed, and to moderate any dominant voice.

All interviews were conducted in the participants' own homes, unless another location was specifically requested.

Interviews were based on the topic guide (Box 1) and were informal in style, enabling specific issues to be explored as and when they arose. All participants were asked to consent to participate, and their capacity to make the specific decision to consent was assessed using a short pro forma, which followed the assessment principles outlined in the Mental Capacity Act 2005. Interviews were digitally recorded, transcribed, and anonymised. At the end of each interview, the researcher summarised the salient points, which were sent to each participant. Follow-up telephone calls corroborated or refined the issues discussed. Researchers kept reflective diaries to record details of each interview, including body language, tone of voice, interview setting, and thoughts about emergent themes and concepts. Both interview summaries and reflective diaries were considered as part of data analysis. Recruitment ceased when new themes ceased to emerge from the data.

Data were subjected to constant comparative analysis, ${ }^{31,37}$ incorporating three iterative steps: (1) transcripts were shared between the team and early impressions noted; (2) transcripts were coded to elicit and incorporate individual perspectives (this involved assigning a label or name to capture sections of the text), manifest codes as well as latent codes were used to develop a thematic table (Table 1); (3) using the thematic table, transcripts were coded. The research team met monthly throughout the data-collection period to discuss the interview process, to share perspectives across the sites, and to discuss emerging ideas and concepts. These meetings helped to refine the thematic table; discussions were recorded, and formed part of the process of data analysis.

Each researcher independently coded a selection of transcripts and discussed the themes emerging. Any discrepancies were resolved by discussion and consensus. NVivo (Version 8) was used to manage data analysis and simplify data retrieval. Only data relating to service pathway (theme 7 , Table 1) are the focus of this article. A fuller description of the research methods used is provided in the study report. ${ }^{37}$

\section{RESULTS}

\section{Study sample}

In total 53 participants were included in the final study: 27 individuals with memory problems and 26 carers; 20 were matched pairs. Participant characteristics are shown in Table 2. Over half the carers were spouses ( $n=15)$; the rest were mostly adult children $(n=3)$ or part of the extended family of their relative with memory problems $(n=2)$. Eight individuals with memory problems had no immediate carer and lived alone.

The type of diagnosis individuals had received ranged from Alzheimer's disease, vascular dementia and, in some cases, $\mathrm{MCl}$ laccording to the Petersen criteria ${ }^{38}$ ). 


\begin{tabular}{|c|c|}
\hline Theme & Subcategories \\
\hline $\begin{array}{l}\text { 1. Advice/help prior } \\
\text { to contacting services }\end{array}$ & $\begin{array}{l}\text { 1. Seeking advice } \\
\text { 2. Receiving advice } \\
\text { 3. Perceived triggers for seeking advice } \\
\text { 4. Barriers to advice }\end{array}$ \\
\hline $\begin{array}{l}\text { 2. Awareness of } \\
\text { cognitive condition }\end{array}$ & $\begin{array}{l}\text { 1. Self-monitoring (relating to the individual with dementia) } \\
\text { 2. Change or transition (relating to the individual with dementia) } \\
\text { 3. Diagnosis (relating to the individual with dementia) } \\
\text { 4. Awareness drift } \\
\text { 5. Views of others }\end{array}$ \\
\hline $\begin{array}{l}\text { 3. Examples of memory } \\
\text { problems/cognitive } \\
\text { impairment }\end{array}$ & $\begin{array}{l}\text { 1. Personal } \\
\text { 2. Previous } \\
\text { 3. Others (media/societal attitude) }\end{array}$ \\
\hline $\begin{array}{l}\text { 4. Response to memory } \\
\text { problems/cognitive } \\
\text { impairment }\end{array}$ & $\begin{array}{l}\text { 1. Normalising } \\
\text { 2. Self-acceptance/resignation } \\
\text { 3. Finding a life philosophy/coping style } \\
\text { 4. Coping strategy } \\
\text { 5. Withdrawal } \\
\text { 6. Not coping }\end{array}$ \\
\hline $\begin{array}{l}\text { 5. Telling/sharing with/ } \\
\text { talking to others } \\
\text { (or lack thereof) }\end{array}$ & $\begin{array}{l}\text { 1. Who } \\
\text { 2. Why } \\
\text { 3. Perceived impact }\end{array}$ \\
\hline $\begin{array}{l}\text { 6. Emotional responses } \\
\text { to the condition/ } \\
\text { process/diagnosis }\end{array}$ & \\
\hline $\begin{array}{l}\text { 7. Service pathway } \\
\text { (including assessment, } \\
\text { disclosure, treatment } \\
\text { and follow-up) }\end{array}$ & $\begin{array}{l}\text { 1. Waiting (subjective experience) } \\
\text { 2. Lack of clarity } \\
\text { 3. Time frame (measurable) } \\
\text { 4. Testing or scoring } \\
\text { 5. Scans } \\
\text { 6. Medical examination (including bloods) } \\
\text { 7. Referral process: by and to whom? } \\
\text { 8. Questions asked } \\
\text { 9. Information received (and type) } \\
\text { 10. Experience of process (include description of and experience of environment) } \\
\text { 11. Satisfaction/dissatisfaction with service } \\
\text { 12. Satisfaction/dissatisfaction with individuals } \\
\text { 13. Initial expectations } \\
\text { 14. What has and has not helped (specific examples) } \\
\text { 15. What could have helped (specific examples) }\end{array}$ \\
\hline $\begin{array}{l}\text { 8. Support (structural, } \\
\text { practical, emotional, } \\
\text { services) }\end{array}$ & $\begin{array}{l}\text { 1. Extended family } \\
\text { 2. Spouse } \\
\text { 3. Friends } \\
\text { 4. Church/religious institution } \\
\text { 5. Day centre/club } \\
\text { 6. Other support (service support) } \\
\text { 7. Absence of support and unmet needs }\end{array}$ \\
\hline \multicolumn{2}{|l|}{$\begin{array}{l}\text { 9. Other support and } \\
\text { information needs }\end{array}$} \\
\hline 10. Future & $\begin{array}{l}\text { 1. Expectations } \\
\text { 2. Hopes } \\
\text { 3. Plans } \\
\text { 4. Fears }\end{array}$ \\
\hline 11. Anti-dementia drugs & $\begin{array}{l}\text { 1. Effect (including side effects) (perceived) } \\
\text { 2. Feelings } \\
\text { 3. Expectations } \\
\text { 4. Management }\end{array}$ \\
\hline
\end{tabular}

The researchers did not seek specific dementia diagnoses from participants after establishing that they had received a diagnosis - as the study focus was on participants' experiences of the process of assessment and diagnosis and what they remembered from it. Of the 27 individuals with memory problems interviewed, eight interviews were conducted with individuals who already had a dementia diagnosis at the time of the first interview. Thirteen subsequently received a diagnosis by the time of the second interview. The rest were still waiting to receive a diagnosis. Those who had received a diagnosis of mild cognitive impairment were expecting to be followed up in 12 months' time.

\section{Themes}

Findings reported in this paper focus predominantly on the assessment and diagnosis process, and expectations of prescribed medication. In relation to these, four cross-cutting themes emerged. First, individuals sought a diagnosis, with the belief that timeliness was important. Secondly, a prolonged diagnostic process may have negative consequences for the person with suspected dementia or their carer. Thirdly, the setting of assessments could shape perceptions of dementia syndrome. Finally, communication between patients, carers, and professionals was not necessarily a dialogue.

\section{Belief in timeliness}

Participants suggested that they were attempting to get to a diagnosis because they believed that catching the disorder early was crucial to receiving treatment for it. Some indicated that this was a result of media messages:

'We're still waiting for something to happen. Because they reckon early diagnosis don't they and then they can do something and try and hold it if that is the case. Give you something to slow it up a bit. But we're still waiting.' (carer: S4-17.2)

\section{Assessment delays matter}

The diagnostic process was described by some as moving slowly along, with significant delay between appointments. However, participants reported having had little expectation of what they were waiting for, and the intervals between appointments for results and explanations were seen by some as burdensome:

'I have no idea how long the process will take ... because we don't know, what the waiting times for these things [are] ... so I don't know, we just wait ... that's why they call us patients isn't it?' (carer: S4-1.1) 
Table 2. Characteristics of participants

\begin{tabular}{|c|c|c|}
\hline & Individuals with memory problems & Carers \\
\hline$n$ & 27 & 26 \\
\hline Male sex & 13 & 6 \\
\hline \multicolumn{3}{|l|}{ Age, years } \\
\hline$<65$ & 4 & 13 \\
\hline $65-79$ & 18 & 12 \\
\hline$\geq 80$ & 5 & 1 \\
\hline Diagnosis of dementia at baseline & 8 & $\mathrm{~N} / \mathrm{A}$ \\
\hline Diagnosis of dementia at follow-up & 21 & $\mathrm{~N} / \mathrm{A}$ \\
\hline \multicolumn{3}{|l|}{ Ethnicity } \\
\hline White British & 24 & 24 \\
\hline White Irish & 1 & 1 \\
\hline South Asian & 1 & 1 \\
\hline Other minority & 1 & 0 \\
\hline \multicolumn{3}{|l|}{ Education } \\
\hline Left school aged $15-17$ years & 17 & $\mathrm{~N} / \mathrm{A}$ \\
\hline Higher education & 10 & $\mathrm{~N} / \mathrm{A}$ \\
\hline \multicolumn{3}{|l|}{ Employment status } \\
\hline Employed, full-time & 0 & 6 \\
\hline Employed, part-time & 2 & 1 \\
\hline Retired: & 25 & 19 \\
\hline \multicolumn{3}{|l|}{ Living arrangements } \\
\hline Alone & 8 & $\mathrm{~N} / \mathrm{A}$ \\
\hline With spouse & 14 & $\mathrm{~N} / \mathrm{A}$ \\
\hline
\end{tabular}

Such delays in the assessment process matter, because it is possible for assumptions to be made during the waiting time; some believed it meant that a diagnosis could not be confirmed. One person with memory problems talked about the disappointment in the system this evoked:

"It took a long time to get ... well not a long time to get on the waiting list, you were told ... they done their own examination and what have you, I don't know exactly what they look for. It took 13 weeks to get through. I wouldn't be telling lies if I wasn't disappointed, perhaps I was anticipating to get through a lot quicker but it went on for a long time.' (individual with memory problem [lwMP]: S2-8]

Uncertainty about the diagnosis and how to respond to it was not resolved - and, in some cases, was exacerbated - by the passage of time:

'It's just the not knowing if it is something that's wrong with you, or if it is just forgetfulness.' (lwMP: S4-8.1)

\section{Settings matter}

Some participants with dementia, and carers, appeared to find the settings of some memory clinics distressing.
Conclusions may be drawn from the setting of the diagnostic assessment, as in the case of individuals who learned their diagnosis in a day hospital for individuals with dementia:

I think the down side of going to the X [day centre] is seeing all of these very old ... probably the same age as me ... because I am old ... but seeing these disabled people and think "oh God is that, you know, going to be the future?" It's a bit sort of ... bringing reality up a little bit close, I think.' (carer: S2-9)

\section{Communication matters}

Communication with professionals was not necessarily a dialogue. In consultations, there was some time for questions; however, mostly individuals did not know what questions to ask or what information they might need. Some felt that they had not received adequate information, while others felt their concerns and questions had been disregarded:

Well, they haven't told me anything, nothing at all. One lady she came with papers, but that was all. I used to speak to the doctor but he said "no you are okay, okay all the time", and so [shrugs]. Well, if there's nothing I can do about it, why bother to know?' (IwMP:S1-3)

Support offered tended to be generic rather than a person-centred response to concerns:

'The thing is I was told that I should get some sort of papers signed, erm, but as I said, somebody said go to the website and download it, I haven't really done that, I mean I emailed her back, the lady who told me to do this in the first place, you know from what's it place, and just said "What exactly do you want me to do? Which form?" you know, and I haven't had access to it since then. ' (carer: S1-3)

Such missed opportunities may mean that professionals are unaware of an individual's apprehensions about their situation or medication:

My next question is when I actually go on [date] because I don't actually know much about the drug, somebody said, "oh you want to be careful because some drugs are experimental" and blah and blah, so I want to make sure, I don't want any experiment ... I know it might sound awful but I don't want any experimental drugs. I want a drug that's sort of been tested and proven, I 


\section{Funding}

NIHR Service Delivery and Organisation (SDO) funding stream (project 08/1809/229). Jill Manthorpe is a member of the Alzheimer's Society and receives funding from the Department of Health and National Institute for Health Research (NIHR) for research studies. Kritika Samsi is funded under a NIHR research programme (EVIDEM). James Warner receives funding from the Medical Research Council and NIHR for research studies. Louise Robinson and Steve lliffe receive NIHR funding for research on dementia.

\section{Ethical approval}

Ethical approval for the study was obtained from Newcastle \& North Tyneside REC 1 (09) H0906/15). Research governance approval was provided by each of the participating NHS trusts.

\section{Provenance}

Freely submitted; externally peer reviewed.

\section{Competing interests}

John Bond is a member of the Alzheimer's Society and is a member of the scientific committee of Alzheimer's Disease International. He has undertaken consultancy work for Pfizer on raising the awareness of dementia and earlier diagnosis. Louise Robinson and Steve lliffe were members of the Department of Health working group that developed the commissioning tool on dementia diagnosis and management (2011). James Warner is a member of the clinical team at Central and North West London NHS Foundation Trust. Sue Watts and John Keady are members of the clinical team at Greater Manchester West Mental Health NHS Foundation Trust. The views and opinions expressed in this paper are those of the authors and do not necessarily reflect those of the NIHR SDO programme or the Department of Health.

\section{Acknowledgements}

We are grateful to the site coordinators and administrators at the four memory services from which the study recruited, and to the national advisory group and the three sitespecific advisory groups for their support and advice. Thanks are due to Kalpa Kharicha and Jessica Hindes for their assistance in this study, and to the study co-grant holders, Professor Claire Goodman (University of Hertfordshire) and Professor Vari Drennan (St George's University of London).

\section{Discuss this article}

Contribute and read comments about this article on the Discussion Forum: http://www.rcgp.org.uk/bjgp-discuss don't want any, you know ... because she's [mother with diagnosis of dementia] got enough problems without adding to them. (carer: S4-8.2)

\section{DISCUSSION}

\section{Summary}

Individuals with suspected dementia who have been referred to a memory clinic may begin the assessment process with the belief that early intervention may slow the disease process. Family members may share this perception. The transition from being muddled or forgetful to having a diagnosis of dementia is characterised by uncertainty and often by lengthy waiting, which may be misunderstood as a sign that a problem is not serious or that the patient is not a priority. The setting where diagnostic assessments take place can adversely affect patients' and carers' perceptions of dementia syndrome. Communication between patients, carers, and professionals was not necessarily a dialogue.

\section{Strengths and limitations}

All qualitative analysis is a process of interpretation, and it is recognised that this can compromise the totality of the qualitative data. ${ }^{39}$ However, the trustworthiness of the data and the analysis of it depend on the credibility of findings and interpretations to others with experience of the topic, the dependability of the research (in terms of the depth of description of methods, and peer analysis of data), and the transferability of the findings to other settings..$^{40}$ Conducting interviews in participants' own homes had the added advantage of this being a familiar place for participants to talk candidly. In some cases, it enabled participants to show letters and appointment cards that were within easy reach, to the researcher

\section{Comparison with existing literature}

To the best of the authors' knowledge, this is the first UK in-depth study of patient and carer perceptions of the assessment and diagnostic process in dementia since the introduction of cholinesterase inhibitors gave fresh impetus to diagnosis. The average age of the study sample mirrors that of recent studies in this area. ${ }^{41}$

\section{Implications for practice}

The findings of this study identify a model of care that could help practitioners support patients through the dementia diagnosis process in three ways: (1) GPs may be more able to provide tailored support to individuals and families at this uncertain time if they are better informed about the diagnostic 'journey' from the insights of those who have undertaken it; (2) expectations about the benefits of early diagnosis should be explored, because they may not be realistic lexploration should also cover expectations of medication, which may over- or underestimate its efficacy); (3) explaining the diagnostic process and reasons for possible delays in it may reduce uncertainty and avert misunderstandings. The lack of dialogue between patients and specialists may also mean that doctors and other practitioners undertaking memory assessments need further training in communication skills. Alternatively, some of the problems of communication might be mitigated by situating memory assessment services in primary care settings that are familiar to individuals and their carers. ${ }^{42-44}$

Policymakers and commissioners need to understand the diagnostic 'journey', which could inform any refreshing or evaluation of the National Dementia Strategy. Policymakers should act cautiously in giving the impression that rapid diagnosis is always possible or desirable. The settings in which the diagnostic process is carried out need to be considered, as policymakers accept, ${ }^{15}$ and more time may be needed to address individual needs for information, ${ }^{43}$ and to tailor advice in this process of 'reflection and adaptation', when immediate reactions to the diagnosis may have had a chance to evolve. ${ }^{3}$

The quality standard for dementia promoted by NICE advises that 'local data collection' will be the means to ensure that its quality standards around information and personalised support are being met..$^{45}$ Commissioners who are seeking to evaluate the quality of memory assessment services will need to capture these insights, and could usefully focus on the duration of the assessment, the settings in which diagnostic assessments are carried out, and the methods of post-diagnostic counselling that are used. Policymakers have been prescriptive about the need for early diagnosis, ${ }^{13,14}$ but commissioners may wish to endorse this as 'timely' and to see all such quality standards as interconnected and important.

While the diagnosis of dementia will be made most often by specialists in memory assessment services, GPs may need to support their patients through a process that can be hazardous for them. Doctors who view dementia in a psychological and social context may be better placed to appreciate and modify the expectations and fears of their patients making the transition from being forgetful to having dementia. ${ }^{46}$ 


\section{REFERENCES}

1. Keady J, Gilliard J. Testing times: the experience of neuropsychological assessment for people with suspected Alzheimer's disease. In: Harris PB (ed.). The person with Alzheimer's disease: pathways to understanding the experience. Baltimore, MD and London: The Johns Hopkins University Press, 2002: 3-28.

2. Corner L, Bond J. Being at risk of dementia: fears and anxieties of older adults. J Aging Stud 2004; 18(2): 143-155.

3. Prince M, Bryce R, Ferri C. World Alzheimer Report 2011: the benefits of early diagnosis and intervention. London: Alzheimer's Disease International, 2011.

4. Limb M. UK government spends $€ 2 m$ to raise awareness of dementia. BMJ 2011; 343: d7235.

5. Oeppen J, Vaupel JW. Demography. Broken limits to life expectancy. Science 2002; 296(5570): 1029-1031.

6. Cognitive function and dementia in six areas of England and Wales: the distribution of MMSE and prevalence of GMS organicity level in the MRC CFA study. The MRC CFAS Medical Research Council Cognitive Function and Ageing Study. Psychol Med 1998; 28: 319-335.

7. Alzheimer's Society. Dementia UK. A report into the prevalence and cost of dementia by the Personal Social Sciences Research Unit (PSSRU) at the London School of Economics and the Institute of Psychiatry at King's College London, for the Alzheimer's Society. London: Alzheimer's Society, 2007.

8. Waldemar G, Phung KTT, Burns A, et al. Access to diagnostic evaluation and treatment for dementia in Europe. Int J Geriatr Psychiatry 2007; 22(1): 47-54.

9. Iliffe S, Manthorpe J. The hazards of early recognition of dementia: a risk assessment. Aging Ment Health 2004; 8(2): 99-105.

10. Apesoa-Varano EC, Barker JC, Hinton L. Curing and caring: the work of primary care physicians with dementia patients. Qual Health Res 2011; 21(11): 14691483

11. Bamford C, Lamont S, Eccles M, et al. Disclosing a diagnosis of dementia: a systematic review. Int J Geriatr Psychiatry 2004; 19(2): 151-169.

12. Leung KK, Finlay J, Silvius JL, et al. Pathways to diagnosis: exploring the experiences of problem recognition and obtaining a dementia diagnosis among Anglo-Canadians. Health Soc Care Community 2011; 19(4): 372-381.

13. Department of Health. Living well with dementia: a national strategy. London $\mathrm{DoH}, 2009$.

14. Department of Health. Quality outcomes for people with dementia: building on the work of the National Dementia Strategy. London: DoH, 2010.

15. Department of Health. Case for change - memory service for people with dementia: evidence. London: $\mathrm{DoH}, 2011$.

16. Bond J. The medicalization of dementia. J Aging Stud 1992; 6: 397-403.

17. Bond J, Corner L, Lilley A, Ellwood C. Medicalisation of insight and caregivers response to risk in dementia. Dementia 2002; 1(3): 313-328.

18. National Institute for Health and Clinical Excellence/Social Care Institute for Excellence. Dementia - supporting people with dementia and their carers in health and social care. London: NICE, 2006.

19. Cutler SJ, Hodgson LG. Anticipatory dementia: a link between memory appraisals and concerns about developing Alzheimer's disease. Gerontologist 1996; 36(5): 657-664

20. Hodgson LG, Cutler SJ. Help seeking for personal concerns about developing Alzheimer's disease. J Appl Gerontol 2004; 23(4): 385-410.

21. Aminzadeh F, Byszewski A, Molnar FJ, Eisner M. Emotional impact of dementia diagnosis: Exploring persons with dementia and caregivers' perspectives. Aging Ment Health 2007; 11(3): 281-290.

22. Clare L. Managing threats to self: awareness in early stage Alzheimer's disease Soc Sci Med 2003; 57(6): 1017-1029.

23. Marzanski M. On telling the truth to patients with dementia. J Med Ethics 2000; 26: $108-113$
24. Hill K, O'Brien J, Morant N, Levy R. User expectation of a memory clinic. Clin Psychol Forum 1995; 83: 9-11.

25. Alzheimer's Society. Information needs of people with dementia and carers. London: Alzheimer's Society, 2010.

26. Van Hout HPJ, Vernooij-Dassen MJFJ, Hoefnagels WHL, Grol RPTM. Measuring the opinions of memory clinic users: Patients, relatives and general practitioners. Int J Geriatr Psychiatry 2001; 16(9): 846-851.

27. van Vliet D, de Vugt ME, Bakker C, et al. Caregivers' perspectives on the pre-diagnostic period in early onset dementia: a long and winding road. Int Psychogeriatr 2011; 23: 1393-1404.

28. Robinson L, Gemski A, Abley C, et al. The transition to dementia - individual and family experiences of receiving a diagnosis: a review. Int Psychogeriatr 2011; 23(7): 1-18.

29. Banerjee $\mathrm{S}$, Willis R, Matthews $\mathrm{D}$, et al. Improving the quality of care for mild to moderate dementia: an evaluation of the Croydon Memory Service Model. Int $J$ Geriatr Psychiatry 2007; 22(8): 782-788

30. Glaser BG, Strauss AL. Theoretical sampling. The discovery of grounded theory strategies for qualitative research. New York, NY: Aldine, 1967: 45-77.

31. Strauss A, Corbin J. Basics of qualitative research: techniques and procedures for developing grounded theory, 2nd edn. Thousand Oaks, CA: Sage Publications, 1998

32. Lamont S, Bamford C, May C, et al. The role of priming networks in diagnostic disclosure in dementia. Gerontologist 2002; 42: 85

33. Hutchings D, Vanoli A, McKeith I, et al. Cholinesterase inhibitors and Alzheimer's disease. Carer and professional factors influencing the use of drugs for Alzheimer's disease in the United Kingdom. Dementia 2010; 9(3): 427-443.

34. Hutchings D, Vanoli A, McKeith I, et al. Good days and bad days: the lived experience and perceived impact of treatment with cholinesterase inhibitors for Alzheimer's disease in the United Kingdom. Dementia 2010; 9(3): 409-425.

35. Clarke C, Keady J, Wilkinson $\mathrm{H}$, et al. Dementia and risk: contested territories of everyday life. J Nurs Healthc Chronic Illn 2010; 2(2): 102-112.

36. Phinney A. Fluctuating awareness and the breakdown of the illness narrative in dementia. Dementia 2002; 1(3): 329-344.

37. Manthorpe J, Samsi K, Campbell S, et al. The transition from cognitive impairment to dementia: older people's experiences. Final report. Southampton: NIHR Service Delivery and Organisation programme, 2010.

38. Petersen RC, Stevens JC, Ganguli M, et al. Practice parameter: early detection of dementia: mild cognitive impairment (an evidence-based review). Report of the Quality Standards Subcommittee of the American Academy of Neurology. Neurology 2001; 56(9): 1133-1142.

39. Burnard P. Qualitative data analysis: using a word processor to categorise qualitative data in social science research. Soc Sci Health 1998; 411): 55-61.

40. Guba E, Lincoln Y. Effective evaluation: improving the usefulness of evaluation results through responsive and naturalistic approaches. San Fransisco, CA: Jossey-Bass, 1981.

41. Gibson AK, Anderson KA. Difficult diagnoses: family caregivers' experiences during and following the diagnostic process for dementia. Am J Alzheimers Dis Other Demen 2011; 26(3): 212-217.

42. Koch T, Iliffe S. Implementing the National Dementia Strategy: case studies from primary care. J Dement Care 2009; 17(6): 26-29.

43. Koch T, Iliffe $\mathrm{S}$. Dementia diagnosis and management: a narrative review of changing practice. Br J Gen Pract 2011; DOI: 10.3399/bjgp11X588493.

44. Lee L, Hillier LM, Stolee $P$, et al. Enhancing dementia care: a primary carebased memory clinic. J Am Geriatr Soc 2010; 58(11): 2197-2204.

45. National Institute for Health and Clinical Excellence. Dementia quality standard. London: NICE, 2010. http://publications.nice.org.uk/dementia-quality-standardqs1 laccessed 26 Nov 2012)

46. Spector A, Orrell M. Using a biopsychosocial model of dementia as a tool to guide clinical practice. Int Psychogeriatr 2010; 22(6): 957-965. 